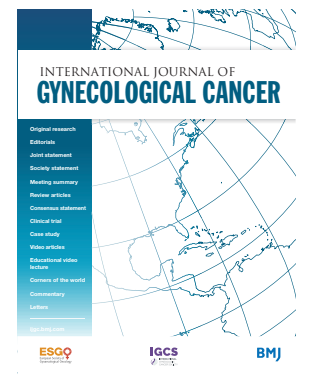

Gynecologic Oncology, Hospital Italiano de Buenos Aires, Buenos Aires, Argentina

Correspondence to Dr Diego Odetto, Gynecology Oncology, Hospital Italiano de Buenos Aires, Buenos Aires, Argentina; diego.odetto@ hospitalitaliano.org.ar

Accepted 20 July 2020 Published Online First 6 September 2020

\title{
Simple trachelectomy with laparoscopic pelvic lymphadenectomy in a pregnant woman with a FIGO stage IA2 cervical cancer
}

Myriam Perrotta, Florencia Noll (D) , Juan Pablo Segundo Cortez, Lucrecia Bolaño, Jose Martin Saadi (1) , Diego Odetto

\section{ABSTRACT}

Cervical cancer although uncommon, with an incidence of 0.8 to 1.5 cases per 10000 births, ${ }^{12}$ is the most frequent gynecologic cancer diagnosed during pregnancy. Treatment always represents an ethical dilemma as options depend on the desire of maintaining the pregnancy, on gestational age, and cancer stage.

In stage IA2-IB1 cervical cancer, with negative nodes and tumor $<2 \mathrm{~cm}$, parametrial extension is $<1 \%{ }^{3}$ Therefore, removing most of the cervix including the tumor with free margins can be a feasible treatment until fetal viability. ${ }^{4}$

We present a 35-year-old patient, G3P1 with a 13 weeks' gestation and a stage IA2 squamous cervical carcinoma. Colposcopy examination showed an extensive ulcerated acetowhite area involving the four quadrants, extending into the endocervical canal. Pelvic examination showed no extension to the vagina or parametrium. Magnetic resonance image showed a $16 \times 12 \times 10 \mathrm{~mm}$ tumor, $18 \mathrm{~mm}$ from the internal orifice with no other abnormal findings.
The patient wished to continue the pregnancy. A simple vaginal trachelectomy and laparoscopic pelvic lymphadenectomy was performed at 15 weeks' gestation. Estimated blood loss was $<300 \mathrm{~mL}$, and surgical time was 170 minutes with no intraoperative complications. The patient was discharged on postoperative day one, after checking fetal vitality.

Final pathology showed a grade 2 squamous cell carcinoma, with $4 \mathrm{~mm}$ depth of invasion and no lymphovascular space invasion: superficial and circumferential extension was of 0.8 and $12 \mathrm{~mm}$ respectively, stage $\mathrm{IA} 2$ according to FIG0 2018.

All margins showed residual high grade squamous intraepithelial lesion (H-SIL). All nodes negative. She delivered a $3250 \mathrm{gm}$ baby by C-section at 38.3 weeks and underwent simple hysterectomy 6 months after giving birth (final pathology showed H-SIL). After 12 months of follow-up she is without evidence of disease (Video 1).

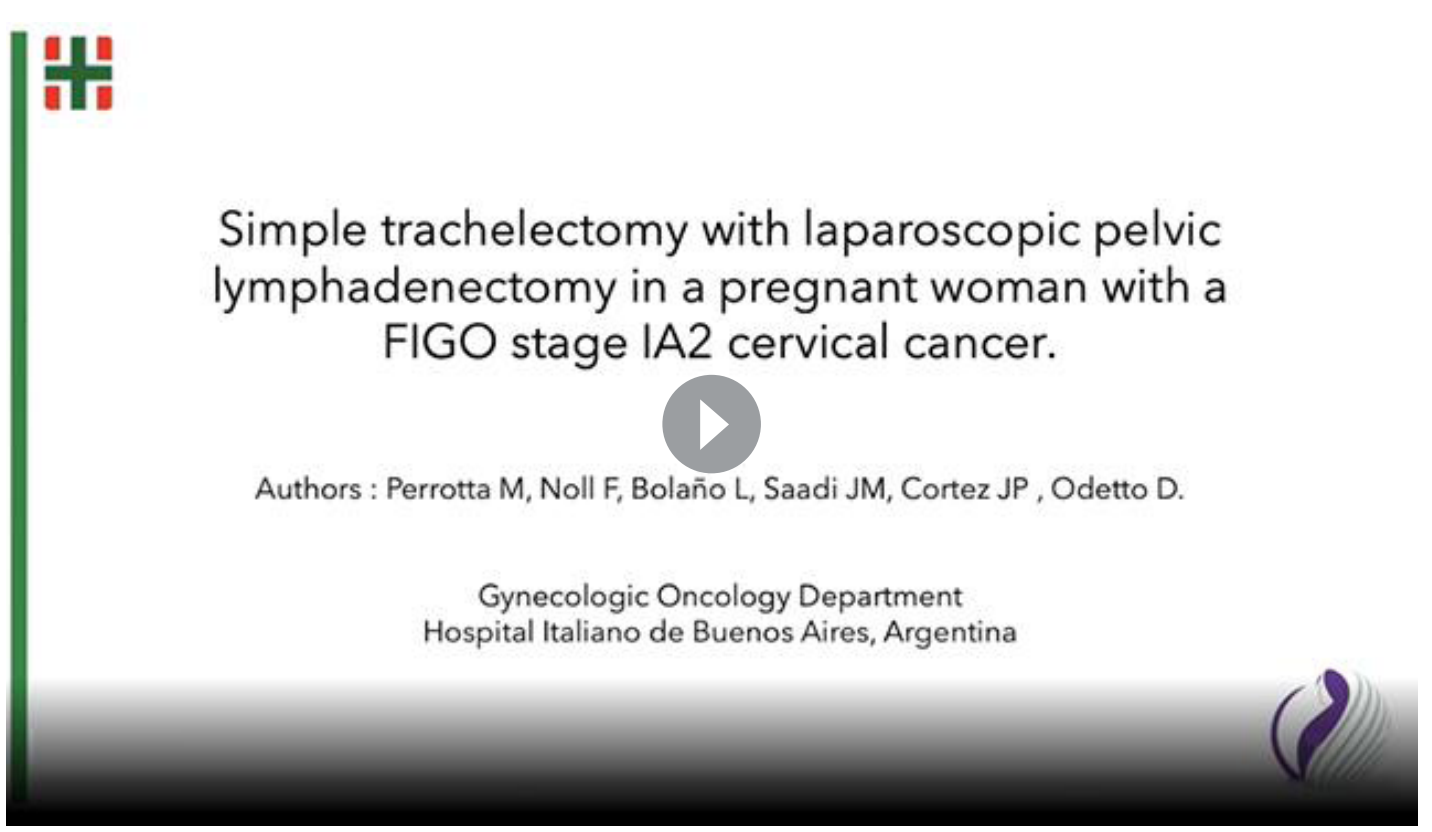

Video 1. This image shows the cervix without evidence of disease after simple trachelectomy at 30 weeks gestation. 
Contributors This video will contribute to the treatment of cervical cancer in pregnancy.

Funding The authors have not declared a specific grant for this research from any funding agency in the public, commercial, or not-for-profit sectors.

Competing interests None declared.

Patient consent for publication Not required.

Provenance and peer review Not commissioned; externally peer reviewed.

Data availability statement All data relevant to the study are included in the article

ORCID iDs

Florencia Noll http://orcid.org/0000-0003-4815-3914

Jose Martin Saadi http://orcid.org/0000-0003-3371-5072

Diego Odetto http://orcid.org/0000-0003-3129-2969

\section{REFERENCES}

1 Morice P, Narducci P, Mathevet H, et al. Darai, French Working Group on Gynecological Cancers in Pregnancy, Société Française d'Oncologie Gynécologique (SFOG), Société Française de Chirurgie Pelvienne (SFCP), Collége National des Gynécologues Obstétriciens Français (CNGOF): French recommendations on the management of invasive cervical cancer during pregnancy. Int $J$ Gynecol Cancer 2009;19:1638-41.

2 Demeter A, Sziller I, Csapó Z, et al. Outcome of pregnancies after cold-knife conization of the uterine cervix during pregnancy. Eur $J$ Gynaecol Oncol 2002;23:207-10.

3 Bentivegna E, Gouy S, Maulard A, et al. Oncological outcomes after fertility-sparing surgery for cervical cancer: a systematic review. Lancet Oncol 2016;17:e240-53.

4 Salvo G, Frumovitz M, Pareja R, et al. Simple trachelectomy with pelvic lymphadenectomy as a viable treatment option in pregnant patients with stage IB1 $(\geq 2 \mathrm{~cm})$ cervical cancer: bridging the gap to fetal viability. Gynecol Oncol 2018;150:50-5. 